\title{
Cardiac Hybrid or Fusion Imaging of CT and SPECT
}

\section{Shinro Matsuo}

Department of Nuclear Medicine, Kanazawa University Hospital, 13-1 Takara-machi, Kanazawa 920-8641, Japan

\begin{abstract}
Cardiac single photon emission computed tomography (SPECT)/computed tomography (CT) has been introduced to provide anatomical information on such as coronary calcification combined with functional information of myocardial perfusion imaging. Fusion imaging provides accurate coregistration of coronary stenosis and perfusion abnormalities, and allows identification of reduced coronary flow reserve. This article shows an overview of relevant literature including clinical value in SPECT/CT.
\end{abstract}

\section{Publication History:}

Received: March 04, 2016

Accepted: July 06, 2016

Published: July 08, 2016

\section{Keywords:}

Hybrid imaging, Fusion, SPECT, CT angiography, Ischemia

\section{Introduction}

Ischemic heart disease is a multifactorial entity that can be diagnosed through non-invasive tests such as nuclear cardiology examination and computed tomography (CT) [1]. The stress myocardial perfusion imaging plays an important role in the risk-stratification of the patients with suspected coronary artery disease, diagnosing the extent and severity of infarction and ischemia induced by both epicardial coronary arteries and resistance vessels [2]. CT coronary angiography can help identify morphological features of coronary arteries [3-4]. If the ischemia-causing coronary stenosis is identified by non-invasive imaging,the culprit lesion can be determined as a therapeutic target of coronary intervention [5]. The relationship between ischemia and coronary artery narrowing can be accurately diagnosed by fusion imaging between single photon emission computed tomography (SPECT)and CT coronary angiography [5]. On the other hand, if the patients with coronary stenosis had developed rich collateral coronary circulation, no ischemic findings on myocardial perfusion imaging might be observed [6]. Additional information on vessel calcification and inflammation can be identified by the CT and the ${ }^{18} \mathrm{~F}$-fluorodeoxyglucose-positron emission tomography (FDG-PET) in the process of coronary artery disease, as well as ischemia and infarction [7]. Recently non-invasive imaging has advanced recently in the field of the nuclear cardiology, includingof SPECT / CT with multifocal collimator and semiconductor detectors, enabling a short acquisition time [8-9]. The SPECT/CT also becomes available and quantifies calcification and cardiac function. This article describes a method of diagnosing though hybrid information from multiple modalities in characterizing the pathophysiology of coronary artery disease.

\section{Anatomic and Physiological Stenosis}

Anatomical information of the coronary arteries can be easily obtained by CT angiography [3-4]. Coronary stenosis is critical target in a strategy of coronary intervention therapy [5]. However, not all of these pathophysiological conditions can be diagnosed by CT information, since small arteries and arterioles level as well as the epicardial coronary artery plays an important role in controlling the coronary circulation at the same time [10]. Actually coronary stenosis on CT may not induce ischemiaon SPECT images [11-12]. Reduced coronary flow reserve might be observed in patients without stenosis $[10,13]$. Myocardial perfusion tracers as ${ }^{201} \mathrm{Tl}$ or ${ }^{99 \mathrm{~m}} \mathrm{Tc}$ agents will be distributed according to the antegrade blood flow and the amount of coronary flow, and also depends on the blood flow of the collateral circulation. Understanding of these physiologiesis essential in order to interpret well a hybrid or fusion imaging.
In addition to the detection of coronary stenosis, important information such as coronary plaque, vascular remodeling, microcalcifications and the myocardial wall thickness could be obtained by the CT scan. Coronary plaque morphology had been intensively investigated [14-15]. There was a good agreement between CT angiography plaque and intravascular ultrasound [16]. Low density CT density or napkinring sign plaque, and thin capfibroatheroma are considered to be suggestive feature for the unstable condition [17-18]. However there might be a long way to use CT plaque information as a clinical indicator for evaluating the prognosis of the patients with stable angina pectoris.

\section{Quantitative Evaluation of Myocardial Ischemia}

The Courage trial nuclear sub-study showed that the subjects with improved perfusion had better prognosis than those without, by using myocardial perfusion imaging [19]. And, the beneficial prognostic result was observed in the patients especially with more than $5 \%$ ischemic improvement through coronary intervention. The incidence of cardiac events for the patients with coronary artery disease becomes higher according to the degree of perfusion defect in stress myocardial perfusion scan [2]. The prognosis of the subjects with coronary artery disease is reportedly improved by performing coronary intervention in patients with more than $10 \%$ ischemia. Therefore, the quantification of the degree of ischemia or infarction is so important in selecting subjects to treat for improving the prognosis. Without using invasive methods such as fractional flow reserve (FFR) measurement by cardiac catheterization, a recent study demonstrated that myocardial perfusion imaging could identify the lesion to be accurately evaluated by non-invasive stress SPECT [21]. Recent advancements of nuclear cardiology techniques support this analysis by novel software. The neural network software called cardioREPO (Fuji Film RI Pharma, Tokyo, Japan), which was developed in collaboration with Exini Co., Sweden.This software can identify the blood flow abnormalities and myocardial ischemia in quantified analysis [21]. Since the amount of ischemia is closely related to the subsequent cardiac death, the precise

*Corresponding Author: Dr. Shinro Matsuo, Department of Nuclear Medicine, Kanazawa University Hospital, 13-1 Takara-machi, Kanazawa 920-8641, Japan; E-mail: smatsuo@nmd.m.kanazawa-u.ac.jp

Citation: Matsuo S (2016) Cardiac Hybrid or Fusion Imaging of CT and SPECT. Int J Radiol Med Imag 2:112. doi: https://doi.org/10.15344/2456-446X/2016/112

Copyright: ( 2016 Matsuo. This is an open-access article distributed under the terms of the Creative Commons Attribution License, which permits unrestricted use, distribution, and reproduction in any medium, provided the original author and source are credited. 
analysis of myocardial ischemic area would becomeso important (Figure 1). Only patients with decreased ischemia demonstrated in myocardial imaging have the benefits of revascularization, including bypass surgery [19]. Meanwhile, when the subject with suspected ischemic heart disease is diagnosed as having normal SPECT, annual hardcardiac events is $0.6 \%$ / per year[22]. The annual hard event rate in asymptomatic patients with type 2 diabetes is $0.8 \%$ / year [23]. The patients with normal myocardial perfusion imaging can recommend to be managedas having a low risk of cardiac event [22-23]. Coronary intervention to the patient without ischemia further may become harmful results in terms of the prognosis. Cardiac event risk could be estimated using myocardial perfusion imaging defect score and left ventricular ejection fraction in conjunction of other clinical information [24]. Thus myocardial perfusion imaging is to help physicians in risk stratification of each patient rather than identifying a per-coronary artery lesions. And we should treat invasively the particular patient with reduced myocardial blood flow reserve [25].

\section{Fusion Imaging of CT Angiography and SPECT}

Contrast $\mathrm{CT}$ coronary angiography is widely used in clinical setting. A multi-slice CT with eight-detector-low had emerged in early 2000 , the diagnostic sensitivity of coronary CT angiography was $75 \%$ when compared to the standard invasive coronary angiography as a reference [4]. CT coronary angiography had advanced then from 16, 32 , and 64 to 320 detectors. The diagnostic performance of coronary CT angiography when compared to invasive coronary angiography has been has been proved to be eligible in many studies with a high specificity. By extracting the coronary arteries obtained from the CT coronary angiography, it is possible to create a fused image of the myocardial perfusion SPECT and CT coronary angiography even if the manufacturers of the SPECT and CT were different $[8,26]$. Organic narrowing lesions of a right coronary artery caused a mild ischemia in the basal inferior wall area of the left ventricle in the case of Figure 2. Culprit coronary artery lesions can be de determined to be the middle right coronary artery in a definitive diagnosis. The perfusion abnormalities in a 83-year-old male with coronary artery bypass surgery could be demonstrated to be due to high lateral branch of the left anterior descending coronary artery, by the fusion imaging (Figure 3). Thus the fusion image enabled the diagnosis of the dominant region of the blood vessel, even after bypass surgery [8].

\section{The Benefits of Fusion Imaging}

Fused SPECT/CT imaging provides an additional clinical value in deciding the strategy of the treatment for the patients with coronary artery disease, as well as inflammatory disease (fugure). The matched finding of ischemia and stenosis indicates a higher incidence of major adverse cardiac events (MACE) [26]. The incidence of MACE in subjects with the unmatched findings was significantly lower than that in matched subjects. Furthermore, when both perfusion and anatomical coronary arteries were normal, the MACE incidence of subjects is the lowest [27-28]. Performing a coronary intervention treatment to the stenoticvessels responsible for ischemia, which were identified by fusion imaging, has a merit of reducing the occurrence of the patient's MACE and improving the prognosis. The fusion imaging is proved to have the advantage that allows the identification of a side-branch ischemia in patients with ischemic heart disease $[8,26]$. However, it is important to read the fusion imaging in familiar with divergence and microcirculation disorders of the coronary arteries, as previously described [13]. The assessment that

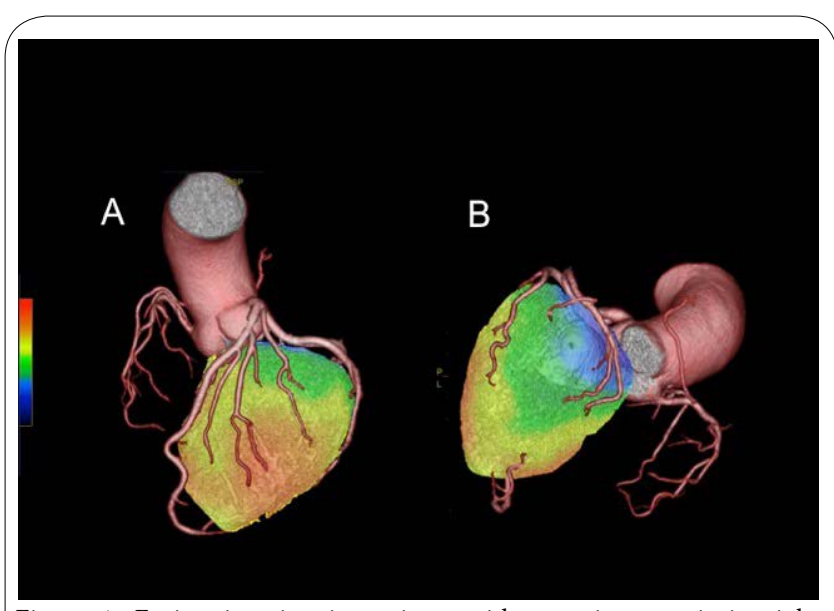

Figure 1: Fusion imaging in patients with organic stenosis in right coronary artery. Culprit lesions of ischemia were determined in both A and $\mathrm{B}$.

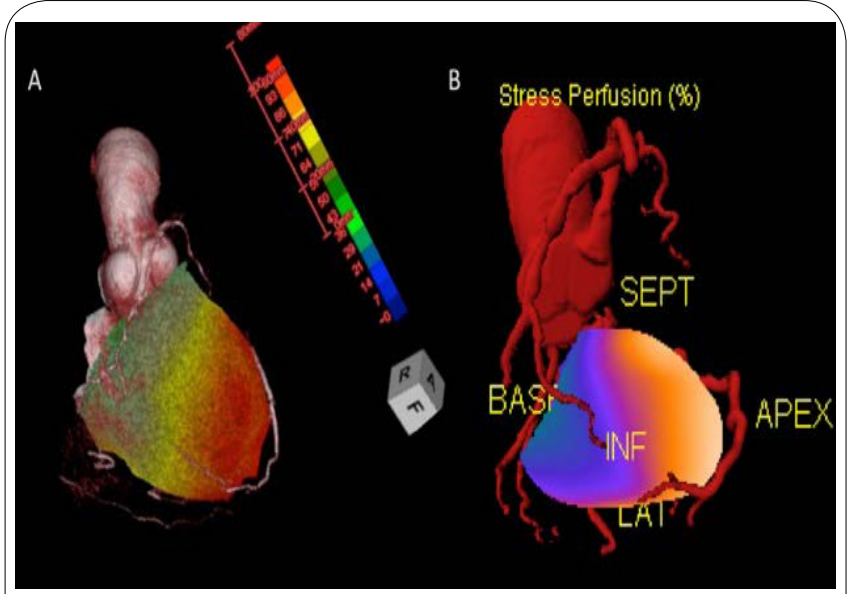

Figure 2: Fusion imaging in a patient with coronary bypass graft. High lateral branch was diagnosed as a culprit lesion. A, polar map.B, fusion imaging.

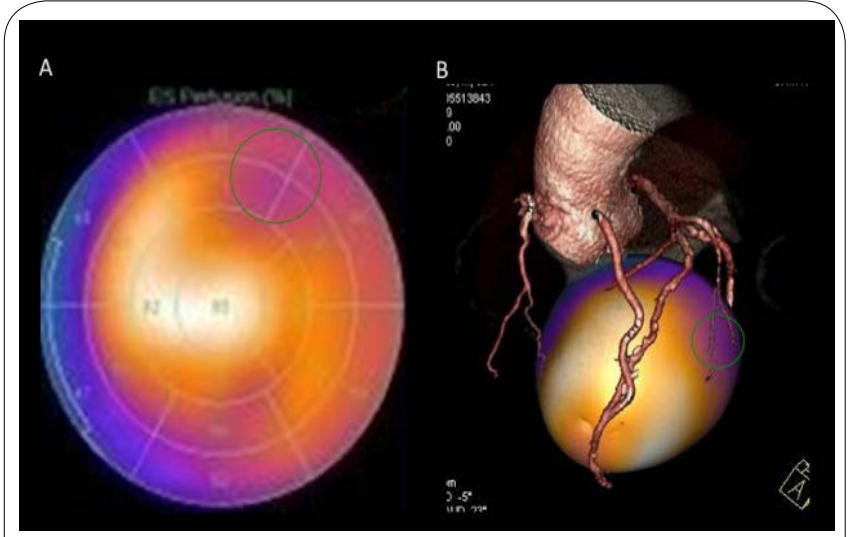

Figure 3: Fusion imaging in a patient without apparent coronay stenosis There was no significant stenosis in left anterior descending coronary artery and left circumflex. However, sight hypo-perfusion in basal inferolateral area was observed.

ischemia is associated with coronary stenosis by the fusion imaging matching, is extremely important in considering the coronary intervention treatment strategy (Figure 1). 
Page 3 of 4

\section{The Coronary Artery Calcification Evaluation by SPECT/CT}

Recently a hybrid SPECT/CT has been introduced and available in clinical evaluation of perfusion and coronary calcification $[11,29]$. The coronary calcification score can be used to estimate the total magnitude of atherosclerotic burden of the coronary arteries. A hybrid SPECT/CT system provides subclinical information of the risk of the patients. The higher the calcification score, the more possibilities of ischemia or infarction exist.

Since myocardial perfusion by SPECT can display a relative perfusion image, balanced ischemia such as multi-vessel coronary arteries may be determined to as ischemia and considered to be normal. However, coronary calcification evaluation may provide additional information. Coronary artery calcification could suggest that the inflammatory lesions had been present previously in the coronary arteries. If severe calcification were observed in patients with score more than 1000 in even normal SPECT, the patients would be considered to have the risk of coronary artery disease. Previous studies demonstrated that it would become possible to carry out improved effective screening by using a combination calcification score and myocardial perfusion SPECT $[7,29]$. The study showed that the subjects with higher calcium score more than 1000 had a trend toward ischemia and infarction [11]. The documentation of coronary calcification as a marker of coronary atherosclerosis can be used to manage the patients with coronary risk factors. Coronary active inflammation observed from the information of FDG-PET may indicateunstable plaque leading to plaque rapture and acute coronary syndrome.

\section{Fusion Diagnosis of Functional Information and Blood Flow}

The exercise or pharmacological stress induces the ischemia, resulting in transient left ventricular cavity dilatation, left ventricularsystolic or diastolic function [30]. Gated SPECT detects these functional changes of left ventricular volumes and ejection fraction. Post-stress dysfunction provides us a diagnostic clue in patients with multi-vessel disease [30-31]. Utilizing these functional information as well as myocardial perfusion, diagnosis of balanced ischemia would become possible. And the transient ischemic dilatation and post-stress dysfunction are the clinical indicators for poor prognosis of ischemic heart disease patients [30].

Multifocal collimators with dedicated reconstruction software and CT have been introduced [9]. This IQ-SPECT system with ${ }^{99 \mathrm{~m}} \mathrm{Tc}$ or ${ }^{201} \mathrm{Tl}$ shortens acquisition times and is clinically applicable in diagnosing patients with high image quality [9]. The cadmium zink-telluride (CZT) cameras provide shorter scan times and higher temporal and spatial resolution than Anger camera [3233]. An experimental pig model reported that the quantification of absolute myocardial blood flow (MBF) measurement could become possible using ${ }^{99 \mathrm{~m}} \mathrm{Tc}$ agents and ${ }^{201} \mathrm{Tl}$ [32]. Fractional flow reserve (FFR) is a clinical indicator for the decision-making of coronary intervention. It may provide better information than angiography alone [34]. Dynamic SPECT (D-SPECT)imaging during first pass of a tracer was attained with the use of CZT camera [33]. Although PET plays a major role in precise evaluation of myocardial flow reserve using ${ }^{13} \mathrm{~N}$-ammonia, ${ }^{82} \mathrm{Rb},{ }^{15} \mathrm{O}$-water and ${ }^{18} \mathrm{~F}$-flupiridaz [3536], myocardial perfusion can be measured in many facilities and enhance the quantitative properties. SPECT quantification may really improve the diagnostic accuracy including the detection of balanced ischemia. The main disadvantage of SPECT in quantification may be underestimation of myocardial flow reserve when compared to that with PET. This limitation of underestimation comes from the lower extraction of ${ }^{99 \mathrm{~m}} \mathrm{Tc}$ agents at high flow.

\section{Conclusion}

In the past few years, nuclear cardiology techniques made a great advancement, including fusion images and SPECT/CT, and have greatly changed by the appearance of a short time acquisition time. The novel hybrid system and fusion imaging to diagnose together with anatomical and functional data provides essential information in considering the therapeutic strategy of coronary intervention.

\section{Competing Interests}

The author has no competing interests with the work presentedin this manuscript.

\section{Author Contributions}

The author substantially contributed to the literature review, drafting the manuscript and approve the final version of the manuscript.

\section{Funding}

The study was supported by JSPS Grant-in-Aid for Scientific Research (C) in Japan (Grant number 23591755). The author appreciates the contributions of the staff of the departments of nuclear medicine, Kanazawa University Hospital.

\section{References}

1. Hachamovitch R, Nutter B, Hlatky MA, Shaw LJ, Ridner ML, et al. (2012) Patient management after noninvasive cardiac imaging results from SPARC (Study of myocardial perfusion and coronary anatomy imaging roles in coronary artery disease). J Am Coll Cardiol 59: 462-474.

2. Nishimura T, Nakajima K, Kusuoka $H$, Yamashina A, Nishimura $S$ (2008) Prognostic study of risk stratification among Japanese patients with ischemic heart disease using gated myocardial perfusion SPECT: J-ACCESS study. Eur J Nucl Med Mol Imaging 35: 319-328.

3. Matsuo S, Horie M (2005) [Cardiovascular imaging by means of multi-slice CT in cardiology]. Nihon Hoshasen Gijutsu Gakkai Zasshi 61: 1309-1317.

4. Matsuo S, Nakamura Y, Matsumoto T, Nakae I, Nagatani Y, et al. (2004) Visual assessment of coronary artery stenosis with electrocardiographicallygatedmultislice computed tomography. Int J Cardiovasclmag 20: 61-66.

5. Koo BK, Erglis A, Doh JH, Daniels DV, Jegere S, et al. (2011) Diagnosis of ischemia-causing coronary stenoses by noninvasive fractional flow reserve computed from coronary computed tomographic angiograms. Results from the prospective multicenter DISCOVER-FLOW (diagnosis of ischemiacausing stenoses obtained via noninvasive fractional flow reserve) study. J Am CollCardiol 58: 1989-1997.

6. Gaemperli O, Schepis T, Valenta I, Koepfli P, Husmann L, et al. (2008) Functionally relevant coronary artery disease: comparison of 64-section CT angiography with myocardial perfusion SPECT. Radiology 248: 414-423.

7. Uebleis C, Becker A, Griesshammer I, Cumming P, Becker C, et al. (2009) Stable coronary artery disease: prognostic value of myocardial perfusion SPECT in relation to coronary calcium scoring--long-term follow-up. Radiology 252: 682-690.

8. Matsuo S, Nakajima K, Akhter N, Wakabayashi H, Taki J, et al. (2009) Clinical usefulness of novel cardiac MDCT/SPECT fusion image. Ann Nucl Med 23: 579-586.

9. Matsuo S, Nakajima K, Onoguchi M, Wakabayash H, Okuda K, et al. (2015) Nuclear myocardial perfusion imaging using thallium-201 with novel multifocal collimator SPECT/CT: IQ-SPECT versus conventional protocols in normal subjects. Ann Nucl Med 29: 452-459. 
10. Matsuo S, Nakamura Y, Matsumoto T, Takahashi M, Kinoshita M (2002) Detection of coronary microvascular disease by means of cardiac scintigraphy. Can J Cardiol 18: 183-186.

11. Matsuo S, Nakajima K, Okuda K, Kinuya S (2011) The relationship between stress-induced myocardial ischemia and coronary artery atherosclerosis measured by hybrid SPECT/CT camera. Ann Nucl Med 25: 650-656.

12. Matsuo S, Matsumoto T, Takashima H, Ohira N, Yamane T, et al. (2004) The relationship between flow-mediated brachial artery vasodilation and coronary vasomotor responses to bradykinin: comparison with those to acetylcholine. J Cardiovasc Pharm 44: 164-170.

13. Mohri M, Koyanagi M, Egashira K, Tagawa H, Ichiki T, et al. (1998) Angina pectoris caused by coronary microvascular spasm. Lancet 351: 1165-1169.

14. Matsumoto N, Sato Y, Yoda S, Nakano Y, Kunimasa T, et al. (2007) Prognostic value of non-obstructive $\mathrm{CT}$ low-dense coronary artery plaques detected by multislice computed tomography. Circ J 71: 1898-1903.

15. Rozanski A, Gransar H, Wong ND, Shaw LJ, Miranda-Peats R, et al. (2007) Clinical outcomes after both coronary calcium scanning and exercise myocardial perfusion scintigraphy. J Am Coll Cardiol 49: 1352-1361.

16. Matsuo S, Nakamura Y, Matsumoto T, Nakae I, Koh T, et al. (2004) Noninvasive evaluation of coronary artery plaque with ECG-gated multislice computed tomography. J Am CollCardiol 43: 363-364.

17. Maurovich-Horvat $\mathrm{P} 1$, Schlett $\mathrm{CL}$, Alkadhi $\mathrm{H}$, Nakano M, Otsuka $\mathrm{F}$, et al. (2012) The napkin-ring sign indicates advanced atherosclerotic lesions in coronary CT angiography. JACC Cardiovasc Imaging 5: 1243-1252.

18. Otsuka K, Fukuda S, Tanaka A, Nakanishi K, Taguchi H, et al. (2013) Napkin-ring sign on coronary CT angiography for the prediction of acute coronary syndrome. JACC Cardiovasc Imaging 6: 448-457.

19. Shaw LJ, Berman DS, Maron DJ, Mancini GB, Hayes SW, et al. (2008) Optimal medical therapy with or without percutaneous coronary intervention to reduce ischemic burden: results from the Clinical Outcomes Utilizing Revascularization and Aggressive Drug Evaluation (COURAGE) trial nuclear substudy. Circulation 117: 1283-1291.

20. Takx RA, Blomberg BA, Aidi HE, Habets J, de Jong PA, et al. (2015) Diagnostic accuracy of stress myocardial perfusion imaging compared to invasive coronary angiography with fractional flow reserve meta-analysis. CircCardiovasc Imaging 8: e002666.

21. Edenbrandt L, Höglund P, Frantz S, Hasbak P, Johansen A, et al. (2014) Area of ischemia assessed by physicians and software packages from myocardial perfusion scintigrams. BMC Med Imaging 14: 5.

22. Matsuo S, Nakajima K, Horie M, Nakae I, Nishimura T; J-ACCESS Investigators (2008) Prognostic value of normal stress myocardial perfusion imaging in Japanese population. Circ J 72: 611-617.

23. Matsuo S, Nakajima K, Yamasaki Y, Kashiwagi A, Nishimura T (2010) Prognostic value of normal stress myocardial perfusion imaging and ventricular function in Japanese asymptomatic patients with type 2 diabetes--a study based on the J-ACCESS-2 database. Circ J 74: 19161921.

24. Nakajima K, Matsuo S, Okuyama C, Hatta T, Tsukamoto K, et al. (2012) Cardiac event risk in Japanese subjects estimated using gated myocardial perfusion imaging, in conjunction with diabetes mellitus and chronic kidney disease. Circ J 76: 168-175.

25. Taqueti VR, Hachamovitch R1, Murthy VL1, Naya M1, Foster CR1, et al. (2015) Global coronary flow reserve is associated with adverse cardiovascular events independently of luminal angiographic severity and modifies the effect of early revascularization. Circulation 131: 19-27.

26. Gaemperli O, Schepis T, Valenta I, Husmann L, Scheffel H, et al. (2007) Cardiac image fusion from stand-alone SPECT and CT: clinical experience. J Nucl Med 48: 696-703.

27. Pazhenkottil AP, Nkoulou RN, Ghadri JR, Herzog BA, Küest SM, , et al. (2011) Impact of cardiac hybrid single-photon emission computed tomography/computed tomography imaging on choice of treatment strategy in coronary artery disease. Eur Heart J 32: 2824-2829.

28. Pazhenkottil AP, Nkoulou RN, Ghadri JR, Herzog BA, Küest SM, et al. (2011) Impact of cardiac hybrid single-photon emission computed tomography/ computed tomography imaging on choice of treatment strategy in coronary artery disease. Eur Heart J 32: 2824-2829.
29. Slart RH, Tio RA, Zijlstra F, Dierckx RA (2009) Diagnostic pathway of integrated SPECT/CT for coronary artery disease. Eur J Nucl Med Mol Imaging 36: 1829-1834.

30. Matsuo S, Matsumoto T, Nakae I, Koh T, Masuda D, et al. (2004) Prognostic value of ECG-gated thallium-201 single-photon emission tomography in patients with coronary artery disease. Ann Nucl Med 18: 617-622.

31. Matsuo S (2012) Phase analysis using gated myocardial perfusion singlephoton emission computed tomography imaging for evaluating cardiac dyssynchrony. Circ J 76: 1832-1833.

32. Wells RG, Timmins R, Klein R, Lockwood J, Marvin B, deKemp RA, et al (2014) Dynamic SPECT measurement of absolute myocardial blood flow in a porcine model. J Nucl Med 55: 1685-1691.

33. Ben-Haim S, Murthy VL, Breault C, Allie R, Sitek A, et al. (2013) Quantification of Myocardial Perfusion Reserve Using Dynamic SPECT Imaging in Humans: A Feasibility Study. J Nucl Med 54: 873-879.

34. Zimmermann FM, De Bruyne B2, Pijls NH3, Desai M4, Oldroyd KG5, et al. (2015) Rationale and design of the Fractional Flow Reserve versus Angiography for Multivessel Evaluation (FAME) 3 Trial: a comparison of fractional flow reserve-guided percutaneous coronary intervention and coronary artery bypass graft surgery in patients with multivessel coronary artery disease. Am Heart J 170: 619-626.

35. Hagemann CE, Ghotbi AA2, Kjær A2, Hasbak P2 (2015) Quantitative myocardial blood flow with Rubidium-82 PET: a clinical perspective. Am J Nucl Med Mol Imaging 5: 457-468.

36. Berman DS, Maddahi J, Tamarappoo BK, Czernin J, Taillefer R, et al (2013) Phase II safety and clinical comparison with single-photon emission computed tomography myocardial perfusion imaging for detection of coronary artery disease: flurpiridaz $\mathrm{F} 18$ positron emission tomography. J Am Coll Cardiol 61: 469-477. 